\title{
Betulinic Acid Exerts Cytotoxic Activity Against Multidrug-Resistant Tumor Cells via Targeting Autocrine Motility Factor Receptor (AMFR)
}

\author{
Mohamed E. M. Saeed ${ }^{1}$, Nuha Mahmoud ${ }^{1}$, Yoshikazu Sugimoto ${ }^{2}$, Thomas Efferth ${ }^{1 *}$ and \\ Heba Abdel-Aziz ${ }^{3 *}$ \\ ${ }^{1}$ Department of Pharmaceutical Biology, Johannes Gutenberg University, Mainz, Germany, ${ }^{2}$ Division of Chemotherapy, \\ Faculty of Pharmacy, Keio University, Tokyo, Japan, ${ }^{3}$ Medical and Clinical Affairs Phytomedicines, Steigerwald \\ Arzneimittelwerk GmbH, Bayer Consumer Health, Darmstadt, Germany
}

Betulinic acid (BetA) is a naturally occurring pentacyclic triterpene isolated from the outer bark of white-barked birch trees and many other medicinal plants. Here, we studied betulinic acid's cytotoxic activity against drug-resistant tumor cell lines. P-glycoprotein (MDR1/ABCB1) and BCRP (ABCG2) are known ATP-binding cassette $(A B C)$ drug transporters that mediating MDR. ABCB5 is a close relative to $A B C B 1$, which also mediates MDR. Constitutive activation of the EGF receptor is tightly linked to the development of chemotherapeutic resistance. BetA inhibited P-gp, BCRP, ABCB5 and mutation activated EGFR overexpressing cells with similar efficacy as their drug-sensitive parental counterparts. Furthermore, the mRNA expressions of ABCB1, BCRP, ABCB5 and EGFR were not related to the 50\% inhibition concentrations $\left(\mathrm{IC}_{50}\right)$ for BetA in a panel of 60 cell lines of the National Cancer Institute (NCI), USA. In addition to well-established MDR mechanisms, we attempted to identify other molecular mechanisms that play a role in mediating BetA's cytotoxic activity. For this reason, we performed COMPARE and hierarchical cluster analyses of the transcriptome-wide microarray-based mRNA expression of the $\mathrm{NCl}$ cell lines panel. Various genes significantly correlating to BetA's activity were involved in different biological processes, e.g., cell cycle regulation, microtubule formation, signal transduction, transcriptional regulation, chromatin remodeling, cell adhesion, tumor suppression, ubiquitination and proteasome degradation. Immunoblotting and in silico analyses revealed that the inhibition of AMFR activity might be one of the mechanisms for BetA to overcome MDR phenotypes. In conclusion, BetA may have therapeutic potential for the treatment of refractory tumors. Keywords: bioinformatics, cancer, drug resistance, microarray, pharmacogenomics, phytotherapy, triterpene,
autocrine motility factor receptor (AMFR)

\section{INTRODUCTION}

Betulinic acid (BetA) is a lupane-type triterpenoid firstly identified and isolated in the 18th century by Johann Tobias Lowitz from the outer bark of white-barked birch trees (Cichewicz and Kouzi, 2004). It can also be found in Vitex negundo (Chandramu et al., 2003), Quisqualis fructus (Woldemichael et al., 2003), Berlinia grandiflora (Enwerem et al., 2001), Tetracentron sinense 
(Yi et al., 2000), Orthosiphon stamineus (Tezuka et al., 2000), Eucalyptus camaldulensis (Siddiqui et al., 2000), Syncarpa glomulifera (Setzer et al., 2000), and Ziziphus spec. (Schühly et al., 1999). BetA possesses several biological activities including antiinflammatory, anticancer, and anti-HIV activities (Cichewicz and Kouzi, 2004). Several studies have been carried out proving the role of BetA and its derivatives in HIV proteases and reverse transcriptase inhibition, suggesting that BetA is a promising candidate for further development to treat HIV (Mayaux et al., 1994; Pengsuparp et al., 1994; Li et al., 2003).

BetA inhibited proliferation and induced apoptosis in various cancer cell lines such as breast, prostate, brain, colon, and leukemia (Fulda et al., 1999; Raghuvar Gopal et al., 2005; Chintharlapalli et al., 2007; Jung et al., 2007; Tiwari et al., 2014). Moreover, BetA has shown in vivo anticancer activity in melanoma and prostate xenograft mouse models (Eiznhamer and Xu, 2004; Chintharlapalli et al., 2007). Interestingly, in vivo studies indicated that BetA has a high safety margin, as systemic side effects were not noticed at the dose range tested (Eiznhamer and $\mathrm{Xu}, 2004$ ). BetA induced apoptosis through affecting mitochondrial membrane potential, leading to increased permeability transition pore openings and production of reactive oxygen species. Subsequently, the release of mitochondrial apogenic factors occurs activating caspases and forming DNA fragments (Fulda et al., 1997, 1998). Furthermore, BetA inhibited aminopeptidase $\mathrm{N}$, an enzyme involved in angiogenesis and metastatic activity during tumor growth (Melzig and Bormann, 1998).

Alternative therapeutic approaches for cancer treatment are urgently needed due to resistance developed toward the vast majority of clinically established anticancer drugs. Thus, implementation of rational alternative medicine using natural products could be one of the choices to overcome drug resistance and to re-sensitize refractory cancer cells to treatment.

The factors involved in multidrug resistance (MDR) are classified into either host factors, in which decreased absorption and distribution with increased metabolism and excretion take place for certain drugs, or cancer cell genetic alterations, in which alternative pathways to evade apoptosis and triggered cell death are activated. Therefore, the design of MDR reversing agents should take into account the factors mentioned above to improve the cancer therapeutic approaches.

Autocrine motility factor receptor (AMFR) is an ubiquitin E3-ligase cell surface glycoprotein, also known as GP78, that is known to play a role in metastasis, tumor progression and recurrence. AMFR regulates cell motility signaling in vitro and metastasis in vivo (Onishi et al., 2003). Furthermore, AMFR is a key player in endoplasmic reticulum-associated degradation (ERAD), targeting misfolded or functionally denatured proteins for proteasome degradation (Halwani et al., 2015). Its ligand, autocrine motility factor (AMF), a motility-stimulating cytokine that is secreted by tumor cells, has been shown to regulate proliferation, tumor migration and apoptosis resistance (Silletti et al., 1991; Shimizu et al., 1999). Recently, the role of AMF in drug resistance has been demonstrated. Kho et al. affirmed that in human breast carcinoma the interaction of AMF with HER2 triggers HER2 phosphorylation and metalloprotease-mediated ectodomain shedding, activating PI3K and MAPK signaling and hinders trastuzumab effect (Kho et al., 2013). Several studies reported the overexpression of AMFR in different types of human cancer, including esophageal carcinoma, breast carcinoma, pulmonary cancer and melanoma (Tímár et al., 2002; Kaynak et al., 2005; Kojic et al., 2007; Wang et al., 2010a).

In the present work, BetA's anticancer activity against drug-resistant tumor cell lines was studied, in which either MDR-conferring ABC-transporters (P-glycoprotein, BCRP, and ABCB5) or mutation-activated EGFR were overexpressed. Furthermore, we investigated the transcriptome-wide mRNA expression profiles of tumor 60 cell lines by COMPARE and hierarchical cluster analyses, to determine multiple other unknown molecular determinants that affect the response of tumor cells to BetA. Using gene-hunting approach, one of the sensitivity determinants genes, AMFR, was selected as a target candidate for BetA. We present novel evidence via molecular docking and immunoblotting analysis that inhibition of AMFR activity might be one of the mechanisms for BetA to overcome MDR phenotypes.

\section{MATERIALS AND METHODS}

\section{Cell Lines}

Drug sensitive CCRF-CEM and multidrug-resistant Pglycoprotein (P-gp)-overexpressing CEM/ADR5000 leukemic cells were cultured in RPMI-1640 medium supplemented with $10 \%$ FBS and $1 \%$ penicillin/streptomycin (Invitrogen, Darmstadt, Germany). Doxorubicin $(5,000 \mathrm{ng} / \mathrm{mL})$ was added to maintain overexpression of P-gp (MDR1, ABCB1) in resistant cells (Kimmig et al., 1990). Breast cancer cells transfected with a control vector (MDA-MB-231-pcDNA3) or with cDNA for the breast cancer resistance protein BCRP/ABCG2 (MDA-MB231-BCRP clone 23) were cultured and maintained as reported (Doyle et al., 1998). Expression of ABCG2 in resistant cells was maintained by geneticin ( $800 \mathrm{ng} / \mathrm{mL}$ ) (Efferth et al., 2003). Human HEK293-ABCB5 embryonic kidney cells transfected with another $\mathrm{ABC}$-transporter, $\mathrm{ABCB} 5$, were propagated in DMEM medium supplemented with $10 \%$ FBS and $1 \%$ penicillin/streptomycin (Invitrogen) (Kawanobe et al., 2012). Non-transfected HEK293 cells served as control. Wild-type human glioblastoma multiform (GBM) U87MG cells and cells transfected with control mock vector or an expression vector harboring EGFR cDNA with a deletion in exons 2-7 (U87MG $\triangle$ EGFR), were kindly provided by Dr. W. K. Cavenee (Ludwig Institute for Cancer Research, San Diego, CA) (Huang et al., 1997).

\section{Cytotoxicity Assays}

The resazurin (Promega, Mannheim, Germany) reduction assay was performed to assess cytotoxicity of BetA in a concentration range of $10^{-5}-100 \mu \mathrm{M}$ as previously described (Kuete and Efferth, 2013). The $\mathrm{IC}_{50}$ values have been calculated from dose response curves and resistance ratios were determined by dividing the $\mathrm{IC}_{50}$ of resistant cells by the $\mathrm{IC}_{50}$ of the corresponding parental cells. Each assay has been done thrice with six replicates for each concentration. 


\section{COMPARE and Hierarchical Cluster Analyses of Microarray Data}

We performed COMPARE analysis for a transcriptome-wide search for correlations between gene expressions and BetA response ( $\log _{10} \mathrm{IC}_{50}$ values) deposited at the NCI website (http:// dtp.nci.nih.gov) to identify candidate genes mediate sensitivity and resistance, respectively, to BetA. This gene-hunting approach is based on Pearson's rank correlation test. To obtain COMPARE rankings, a scale index of correlation coefficients ( $R$-values) has been generated.

Using the CIMMINER program (https://discover.nci.nih.gov/ cimminer/), we performed agglomerative hierarchical cluster analysis (WARD method) to cluster the mRNA expression of genes identified by COMPARE analysis and a heatmap was prepared accordingly.

Pearson's correlation test was used to calculate significance values and rank correlation coefficients as a relative measure for the linear dependence of two variables. The $\chi^{2}$ test was done using the Excel program to proof the frequency distributions for pairs of observed and expected variables for dependencies obtained from cluster analysis/heat mapping.

\section{Western Blotting Analysis}

Both sensitive and resistant breast cancer cell lines ( $10^{6}$ cells/well) were treated with varying concentrations of BetA, harvested after $24 \mathrm{~h}$, and washed with PBS. Using M-PER ${ }^{\mathrm{TM}}$ mammalian protein extraction buffer (Thermo Fisher Scientific), the entire proteins were extracted from the cell lysates. Then, sodium dodecyl sulfate polyacrylamide gel electrophoresis was performed to isolate the proteins, the proteins were then transferred to polyvinylidene fluoride membranes (Ruti ${ }^{\circledR}$-PVDF) (Millipore, Billerica, MA, USA) for western blotting. Five percent of bovine serum albumin was used to block the membranes and then the membranes were incubated with specific primary antibodies against AMFR $(1: 1,000)$ (Thermoscientific, Darmstadt, Germany) and $\beta$-actin (1:2,000) (Cell Signaling Technology, Frankfurt, Germany). The blots were probed with horseradish peroxidase-linked IgG secondary antibodies $(1: 2,000)$ for $2 \mathrm{~h}$ at room temperature. Finally, LuminataTM Classico Western HRP substrate (Merck Millipore, Schwalbach, Germany) was added for $5 \mathrm{~min}$ in the dark. Alpha Innotech FluorChem Q system (Biozym, Oldendorf, Germany) was used for documentation and band analysis.

\section{Molecular Docking}

Molecular docking was done in an approach previously reported by us (Saeed et al., 2018). Briefly, the PDB files of different AMFR cytosolic $\mathrm{C}$ terminal domains and AMF were obtained from protein data bank (registered ids are shown in Table 3). Using AutodockTools-1.5.6rc3, the proteins' PDB files were converted to PDBQT format and set as the macromolecule, upon which docking is to be performed. $2 \mathrm{D}$ structures of the BetA was constructed and later converted to $3 \mathrm{D}$ structures using Corina Online Demo. A grid box was allocated to define docking spaces upon the macromolecule. Energies for each atom type in the ligand were calculated at each grid point using Autogrid 4.2. These calculated energies were later used to predict binding affinity of BetA. Docking was carried out using Autodock 4.2 with 250 runs and 2.5 million evaluations for each cycle via the Lamarckian algorithm. Lowest binding energies were retrieved from the correspondent dlg file and amino acids were analyzed by Autodock Tools. Images were created using Visual Molecular Dynamics VMD.

\section{RESULTS}

\section{Cytotoxic Response of Betulinic Acid in Drug-Resistant Tumor Cell Lines}

In order to study whether or not the classical MDR mechanisms impede the cytotoxic activity of BetA toward cancer cells, we investigated multidrug-resistant P-glycoprotein (MDR1/ABCB1)-overexpressing CEM/ADR5000 cells and drug-sensitive parental CCRF-CEM cells using a resazurin assay. No cross-resistance of the CEM/ADR5000 cells was observed (0.8-fold, Figure 1A).

As other cell models that overexpress $\mathrm{ABC}$ transporters, we tested MDA-MB-231 cells transfected with BCRP/ABCG2 and HEK-293 cells transfected with ABCB5. Both cell lines were sensitive to BetA, if compared with their drug-sensitive parental cells (0.9 and 1.2-fold, respectively (Figures 1B,C).

U87.MG cells transfected with a deletion-activated EGFR cDNA showed similar sensitivity to BetA than their wild-type counterpart (Figure 1D).

\section{Analysis of Classical Drug Resistance Mechanisms for Betulinic Acid}

Pearson's correlation coefficient was used to correlate the expression data of different genes that are responsible for anticancer drug resistance (ABCB1, ABCC1, ABCG2 and $\mathrm{ABCB} 5, \mathrm{EGFR}$, and mutated TP53) with the $\log _{10} \mathrm{IC}_{50}$ values of the NCI cell line panel for BetA. We analyzed microarray, protein array, cDNA sequencing, RT-PCR-based mRNA expressions for the mentioned genes. As shown in Table 1, these parameters did not significantly correlate with the $\log _{10} \mathrm{IC}_{50}$ values for BetA, indicating that its cellular cytotoxicity was not affected by these drug resistance mechanisms. For the validity of our approach, positive control drugs have been used, which were strongly correlated with their corresponding mechanisms of resistance (daunorubicin for $\mathrm{ABCB} 1$, maytansine for $\mathrm{ABCB}$, vinblastine for $\mathrm{ABCC} 1$, pancratistatin for $\mathrm{ABCG} 2$, erlotinib for EGFR and 5-fluorouracil for mutated TP53; Table 1).

\section{Drug Class Profiling}

In order to get a clue about possible modes of action of BetA (Figure 2A), BetA's $\log _{10} \mathrm{IC}_{50}$ values of the NCI cell lines were correlated with standard anticancer drugs (Figure 2C). The cellular response of platinum compounds, alkylating agents, tubulin inhibitors and tyrosine kinase inhibitors were significantly correlated with those of BetA.

\section{Tumor-Type Dependent Response Toward Betulinic Acid}

If the average $\log _{10} \mathrm{IC}_{50}$ values over the entire range of 60 cell lines were diversified regarding their tumor types, Melanoma cell 


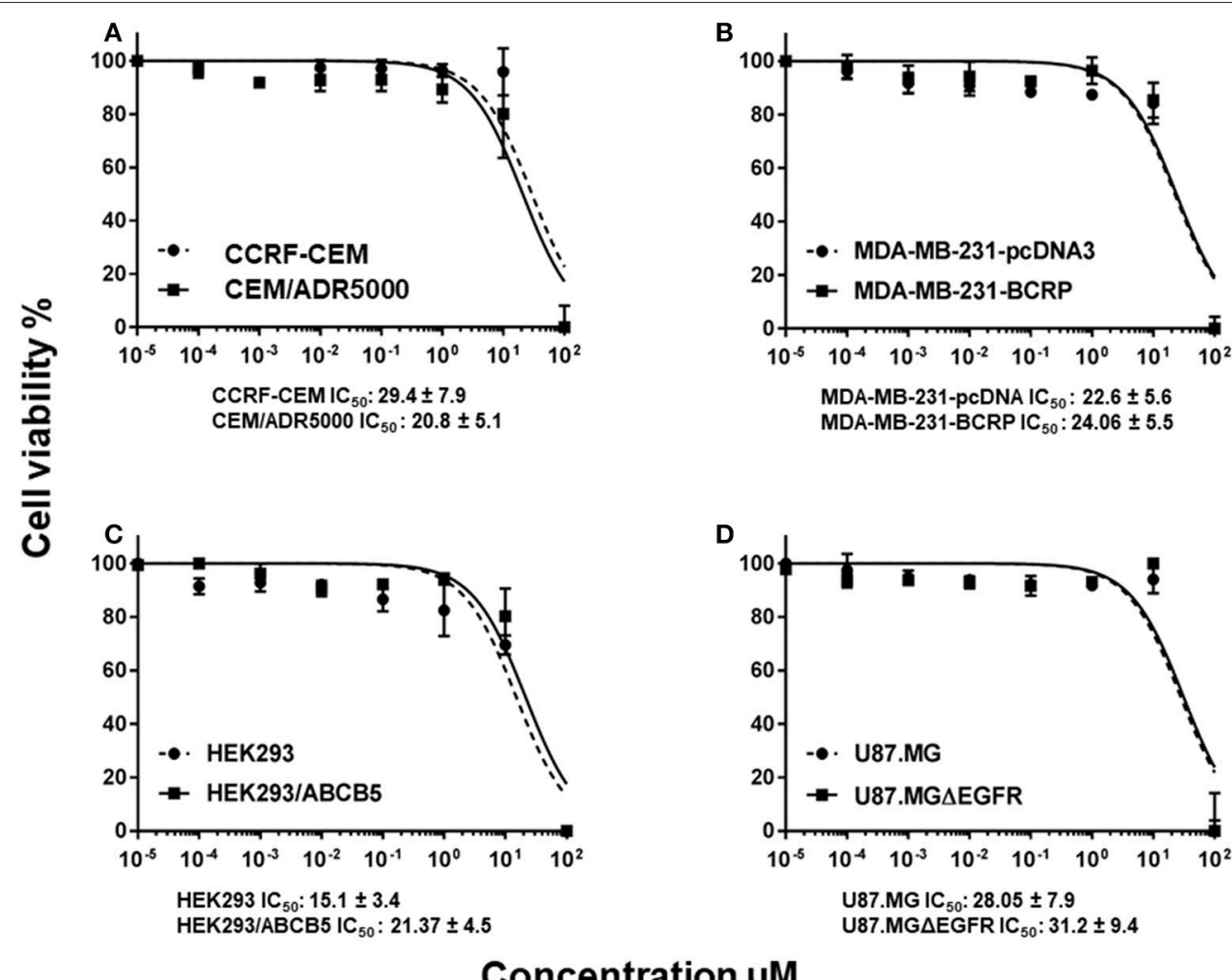

FIGURE 1 | Dose response curves of BetA. (A) Cytotoxicity of BetA toward drug-sensitive parental CCRF-CEM tumor cells and their P-glycoprotein (MDR1/ABCB1)-expressing, multidrug-resistant subline, CEM/ADR5000. (B) Cytotoxicity of BetA toward MDA-MB-231-pc DNA cells and their BCRP-transduced subline, MDA-MB-231-BCRP as determined by resazurin assays. (C) Cytotoxicity of BetA toward HEK293 cells and their ABCB5-transfectant subline, HEK293/ABCB5 as determined by resazurin assays. (D) Cytotoxicity of BetA U87MG cells and their EGFR- transduced subline U87MG $\Delta$ EGFR, as determined by resazurin assays.

lines were most resistant toward BetA, whereas leukemia cell lines were most sensitive (Figure 2B).

\section{Microarray-Based Expression Profiling to Predict Sensitivity and Resistance to Betulinic Acid}

To figure out genes that are mediated sensitivity or resistance of cancer cells toward BetA, we obtained the transcriptome-wide mRNA expressions of the NCI cells and correlated them with the $\log _{10} \mathrm{IC}_{50}$ values for BetA. Using Pearson's rank correlation, we carried out a transcriptome-wide COMPARE analysis to determine genes, whose mRNA expression directly or inversely correlated with the $\log _{10} \mathrm{IC}_{50}$ values for BetA. Fourty genes were identified, half of them were directly and the other half were inversely correlated to the $\log _{10} \mathrm{IC}_{50}$ values for BetA (Table 2 ). The proteins encoded by these genes have diverse biological functions (Table 2).

The mRNA expression values of all NCI cell lines for the genes listed in Table 2 were subsequently subjected to hierarchical cluster analysis, in order to find out, whether clusters of cell lines could be identified with similar behavior after treatment with BetA. The dendrogram of the cluster analysis showed seven main branches in the cluster tree that depicted in the heatmap (Figure 3). As a next step, the $\log _{10} \mathrm{IC}_{50}$ values for BetA, which were not included in the cluster analysis, were assigned to the corresponding position of the cell lines in the cluster tree. The distribution among the seven clusters was significantly different from each other $(P=0.003)$. Clusters 5,6 , and 7 contained in its majority of cell lines sensitive to BetA, whereas clusters 1, 2, 3, and 4 contained in its majority resistant ones.

\section{Western Blotting Analysis}

The role of AMFR in drug resistance and tumor progression is well affirmed (Kho et al., 2013). Interestingly, better correlation between the expression values of AMFR and $\log _{10} \mathrm{IC}_{50}$ values for BetA in sensitive NCI cell lines was observed. This prompted us to investigate whether the expression of AMFR in our MDR cells model will be affected when treated with BetA or not. Therefore, we performed western blot analysis after treating breast cancer cell lines with varying concentration of BetA. The results showed that BetA was able to inhibit expression of AMFR in a dose dependent manner (Figure 4).

\section{Molecular Docking}

To understand the mode of binding of AMFR and its ligand AMF to BetA, we performed molecular docking analysis. BetA 
TABLE 1 | Correlation of $\log _{10} I_{50}$ values for BetA to drug resistance mechanisms (ABCB1, ABCB5, ABCC1, ABCG2, EGFR, TP53) in the $\mathrm{NCl}$ cell line panel.

\begin{tabular}{|c|c|c|c|}
\hline & & Betulinic acid & Control drug \\
\hline & & $\left(\log _{10} I C_{50}, M\right)$ & $\left(\log _{10} I_{50}, M\right)$ \\
\hline ABCB1 expression & & & Daunorubicin \\
\hline 7q21 (chromosomal & $R$-value & -0.004 & *0.597 \\
\hline Locus of ABCB1 gene) & $P$-value & 0.489 & * $4.82 \times 10^{-6}$ \\
\hline ABCB1 expression & $R$-value & 0.036 & ${ }^{\star} 0.684$ \\
\hline (Microarray) & $P$-value & 0.394 & ${ }^{\star} 1.57 \times 10^{-8}$ \\
\hline ABCB1 expression & $R$-value & 0.153 & ${ }^{\star} 0.579$ \\
\hline (RT-PCR) & $P$-value & 0.142 & ${ }^{*} 4.19 \times 10^{-6}$ \\
\hline Rhodamine 123 & $R$-value & 0.076 & ${ }^{\star} 0.544$ \\
\hline Accumulation & $P$-value & 0.286 & ${ }^{\star} 1.51 \times 10^{-5}$ \\
\hline ABCB5 expression & & & Maytansine \\
\hline ABCB5 expression & $R$-value & 0.052 & ${ }^{\star} 0.454$ \\
\hline (Microarray) & $P$-value & 0.347 & ${ }^{\star} 6.67 \times 10^{-4}$ \\
\hline ABCB5 expression & $R$-value & 0.164 & ${ }^{\star} 0.402$ \\
\hline (RT-PCR) & $P$-value & 0.105 & ${ }^{*} 0.0034$ \\
\hline ABCC1 expression & & & Vinblastine \\
\hline DNA gene & $R$-value & 0.148 & *0.429 \\
\hline Copy number & $P$-value & 0.131 & ${ }^{\star} 0.001$ \\
\hline ABCC1 expression & $R$-value & -0.070 & ${ }^{\star} 0.399$ \\
\hline (Microarray) & $P$-value & 0.302 & ${ }^{\star} 0.002$ \\
\hline ABCC1 expression & $R$-value & -0.091 & 0.299 \\
\hline (RT-PCR) & $P$-value & 0.269 & *0.036 \\
\hline ABCG2 expression & & & Pancratistatin \\
\hline ABCG2 expression & $R$-value & -0.092 & *0.329 \\
\hline (Microarray) & $P$-value & 0.246 & ${ }^{\star} 0.006$ \\
\hline ABCG2 expression & $R$-value & -0.051 & ${ }^{\star} 0.346$ \\
\hline (Western blot) & $P$-value & 0.352 & ${ }^{\star} 0.004$ \\
\hline EGFR expression & & & Erlotinib \\
\hline EGFR gene & $R$-value & -0.036 & -0.245 \\
\hline Copy number & $P$-value & 0.394 & ${ }^{\star} 0.029$ \\
\hline EGFR expression & $R$-value & 0.192 & ${ }^{*}-0.458$ \\
\hline (Microarray) & $P$-value & 0.071 & ${ }^{\star} 1.15 \times 10^{-4}$ \\
\hline EGFR expression & $R$-value & 0.203 & ${ }^{*} 0.409$ \\
\hline (RNAse protection) & $P$-value & 0.064 & ${ }^{\star} 7.08 \times 10^{-4}$ \\
\hline EGFR expression & $R$-value & -0.025 & *-0.376 \\
\hline (Protein array) & $P$-value & 0.425 & ${ }^{\star} 0.001$ \\
\hline TP53 mutation & & & 5-Fluorouracil \\
\hline TP53 mutation & $R$-value & -0.066 & ${ }^{*}-0.502$ \\
\hline (cDNA sequencing) & $P$-value & 0.312 & ${ }^{*} 3.50 \times 10^{-5}$ \\
\hline TP53 function & $R$-value & 0.012 & * -0.436 \\
\hline (Yeast functional assay) & $P$-value & 0.464 & ${ }^{*} 5.49 \times 10^{-4}$ \\
\hline
\end{tabular}

${ }^{*} P<0.05$ and $R>0.3$ (or $R<-0.3$ ).

was docked on three different domains which are of crucial importance for AMFR function (CUE domain functions to help substrate binding for ubiquitination, E2 ubiquitin-conjugating enzyme binding domain, and p97/VCP binding domain that participates in the final step of endoplasmic reticulum-associated degradation). In addition to its ligand AMF. As shown in Table 3, the BetA bound to the three different domains in similar affinity $(\approx-6.5 \mathrm{kcal} / \mathrm{mol})$, whereas, it showed higher affinity to AMF with binding energy of $-7.26 \mathrm{kcal} / \mathrm{mol}$. The corresponding docking positions of BetA into binding pockets of AMFR domains and AMF are depicted in Figure 5.

\section{DISCUSSION}

In this study, we investigated the cytotoxic activity of BetA against multidrug-resistant cancer cells and determined the molecular mechanisms associated with either sensitivity or resistance of cancer cells toward BetA. Therefore, we treated cancer cell lines expressing different MDR conferring genes (P-glycoprotein, BCRP, ABCB5 and mutation-activated EGFR) with BetA. To determine the molecular mechanisms, we mined the NCI's Developmental Therapeutics Program database for the documented screening of BetA with a panel of 60 cancer cell lines. The rationale of this approach was to define genes, whose expressions correlated to the pattern of cellular responsiveness to BetA. The genes assessed by this approach belonged to diverse classes, e.g. oncogenes, tumor suppressor genes, drug resistance mediating transporters, heat shock proteins, telomerase, cytokine receptors, molecules of the cell cycle and apoptotic pathways, DNA repair enzymes, components of cytoskeleton, intracellular signaling molecules, and enzymes of metabolism (Monga and Sausville, 2002).

Various mechanisms contribute to MDR in cancer cells. The dominant and possibly the most scrutinized one is drug efflux by a large superfamily of ATP-dependent efflux pumps, i.e., the ATP binding cassette (ABC) transporters (Ueda et al., 1986; Doyle et al., 1998). This superfamily belongs to one of the largest and most distributed superfamilies through all phyla, from prokaryotes to humans (Genovese et al., 2017). In normal eukaryotic cells, most $\mathrm{ABC}$ superfamily members export metabolites and xenobiotics outside cell membranes. Opportunistically, tumors take advantage of this normal function by overexpressing $\mathrm{ABC}$ transporters, subsequently, enhancing the expelling of chemotherapeutic drugs outside of the cells. Interestingly, the three tumor cell lines that overexpress three ABC transporters, P-gp, BCRP and ABCB5 did not confer resistance to BetA. These results showed that BetA is not a substrate of any of the three-abovementioned $A B C$ transporters and indicate that refractory tumors overexpressing these transporters may effectively respond to BetA.

The epidermal growth factor receptor (EGFR) family activates signaling pathways regulating cellular proliferation, angiogenesis initiation, apoptosis inhibition and survival, which subsequently results in increasing tumor masses and chemotherapy refractoriness. In glioblastoma tumors, the common EGFR mutation is in frame deletion of exon 2-7 resulting in ligand-binding domain deletion of the EGFR (Nishikawa et al., 1994; Shinojima et al., 2003). This deletion causes constitutive activation of the receptor in the absence of 
A

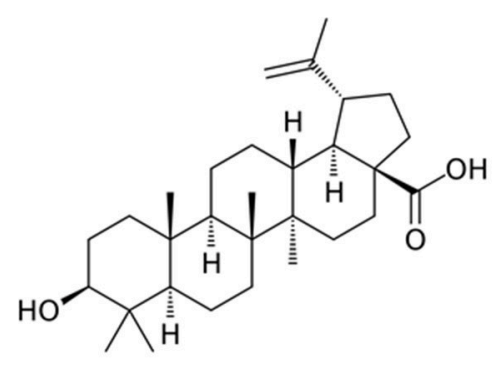

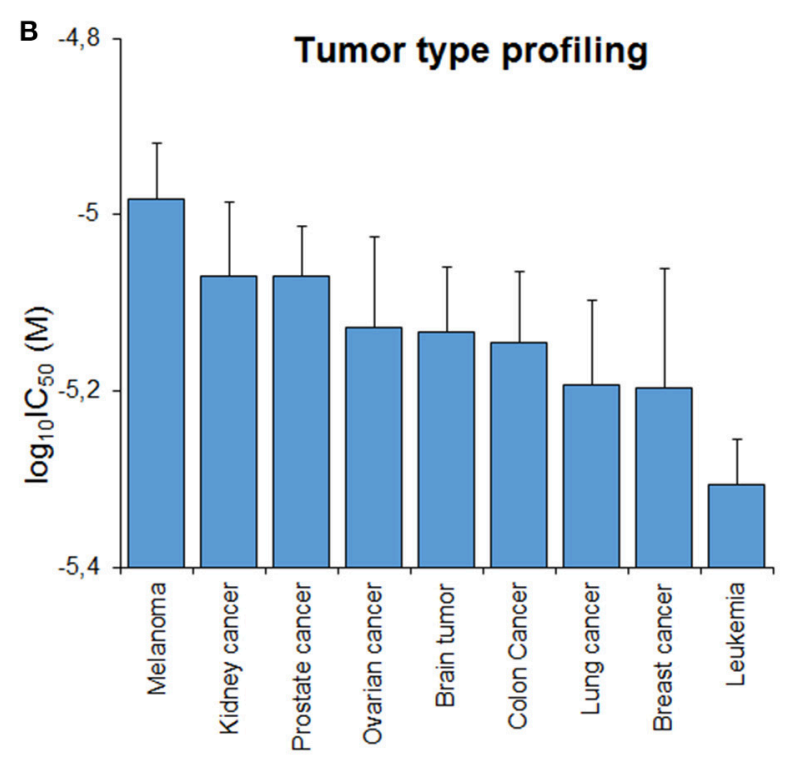

C

\section{Drug class profiling}

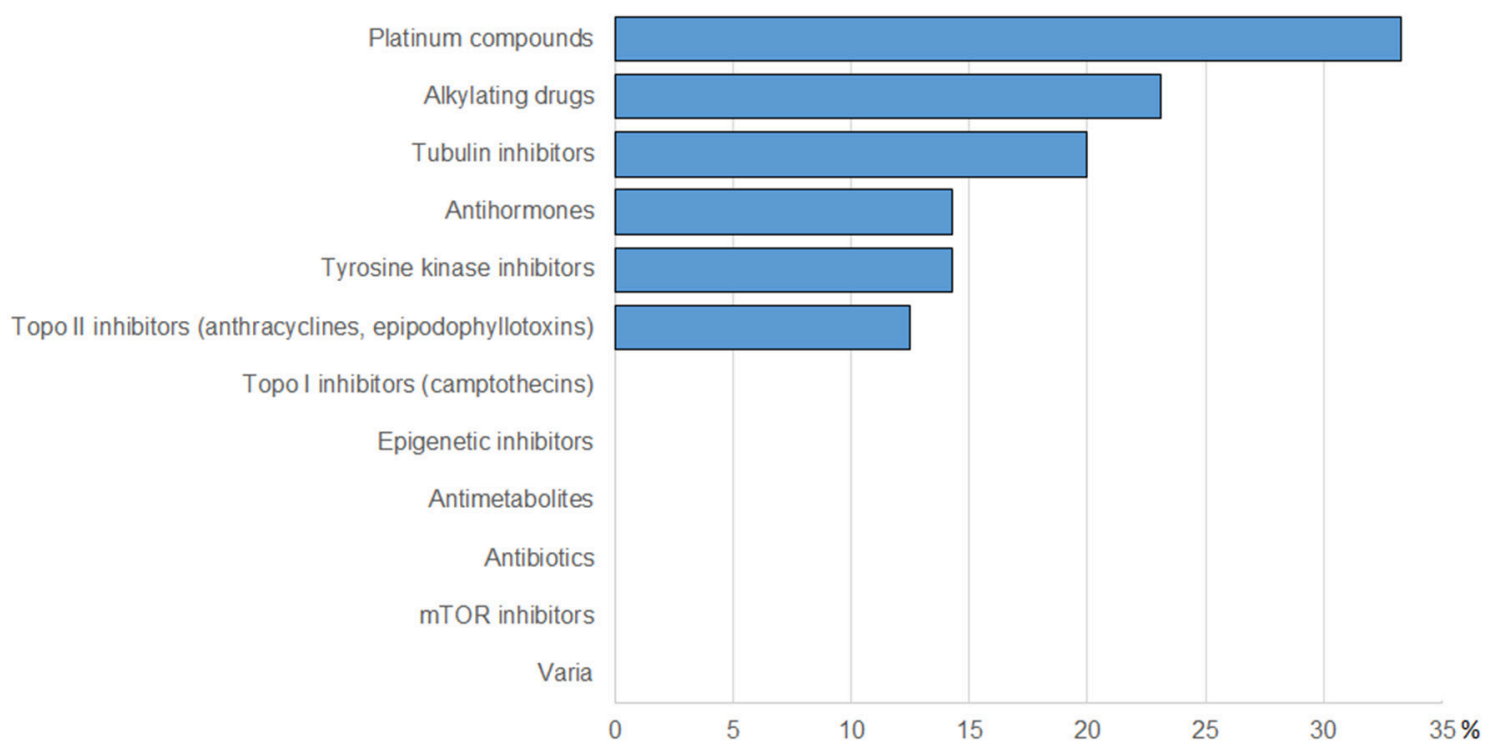

FIGURE 2 | (A) Chemical structure of BetA. (B) Mean $\log _{10} I_{5} C_{50}$ values for BetA of the $\mathrm{NCl}$ cell lines, and S.E.M. $\log _{10} \mathrm{IC}_{50}$ values were grouped according to the tumor type of the cell lines. (C) Percentage of classes of established anticancer drugs, whose $\log _{10} \mathrm{IC}_{50}$ values correlate with those for BetA.

ligand binding (Kuan et al., 2000; Arteaga, 2002). The autoactivated receptor phosphorylates tyrosine in the intracellular domain of the receptor, leading to activation of downstream signaling cascades. We tested the BetA effect on tumor cells transduced with mutated EGFR gene (resistant) and its sensitive parental cell line. BetA killed both cell lines at the same concentrations, showing that $\triangle \mathrm{EFGR}$ does not confer resistance toward BetA.

Since the established MDR mechanisms investigated in this study were not involved in resistance toward BetA, we performed a microarray-based transcriptome wide screening of genes using COMPARE analysis, whose mRNA expression correlated with the $\log _{10} \mathrm{IC}_{50}$ values for BetA. Genes from diverse biological groups were identified to be correlated with the $\log _{10} \mathrm{IC}_{50}$ values for BetA, e.g., genes involved in cell cycle regulation and microtubule formation (CHEK2, CDC25C, KIFC1, PTP4A2, CKS1B, CEP170B), signal transduction and transcriptional regulation (GNG5, GNG12, PPP2R4, ERBB3, ZNF652, FAM50A), protein synthesis (NVL, LSM2, ERN1, KANK1), chromatin remodeling (FBL, DNTTIP2, $C B X 5)$, cell adhesion (ADAM3A, PTPRJ), tumor suppression (SASH1, WWTR1), ubiquitination and proteasome degradation 


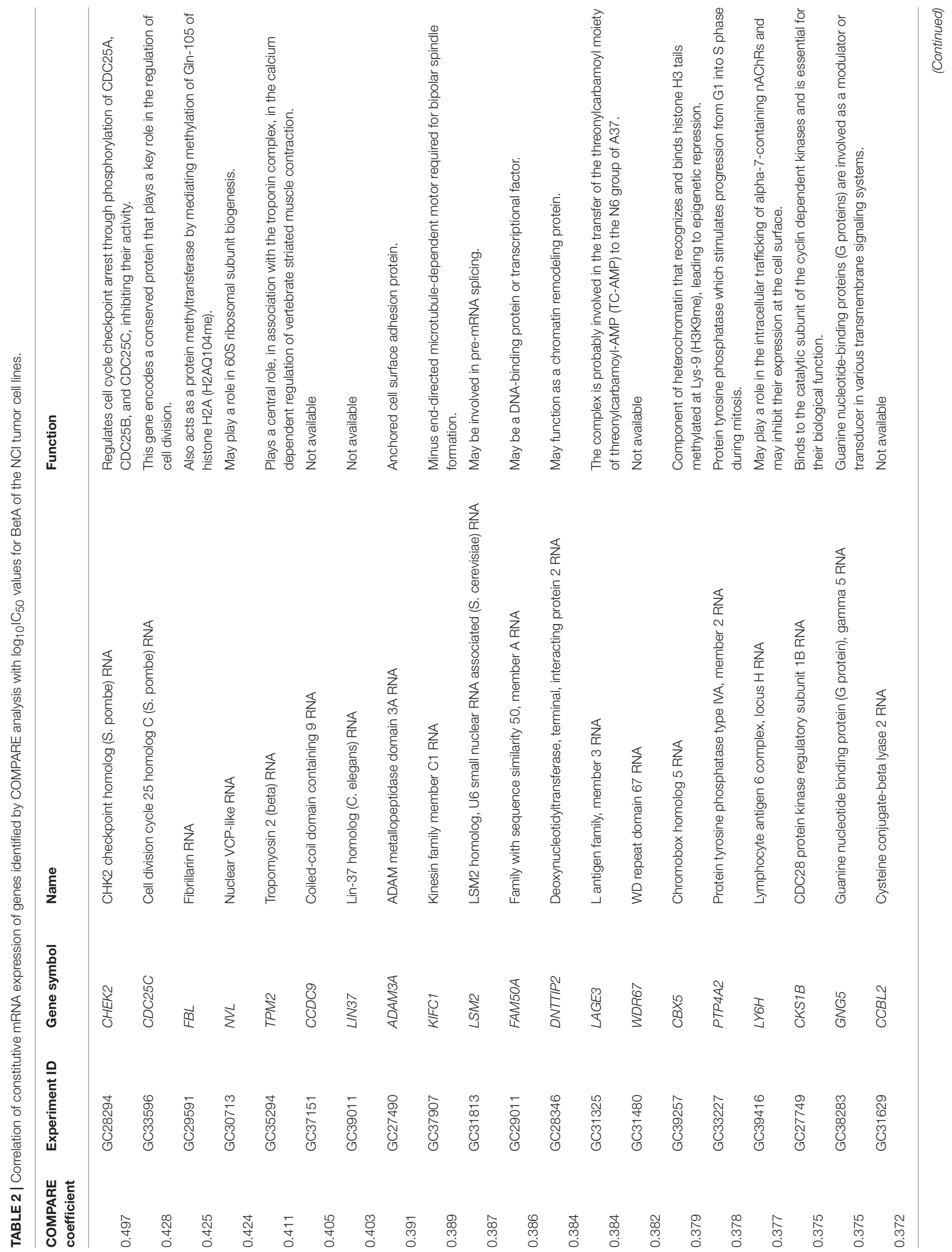




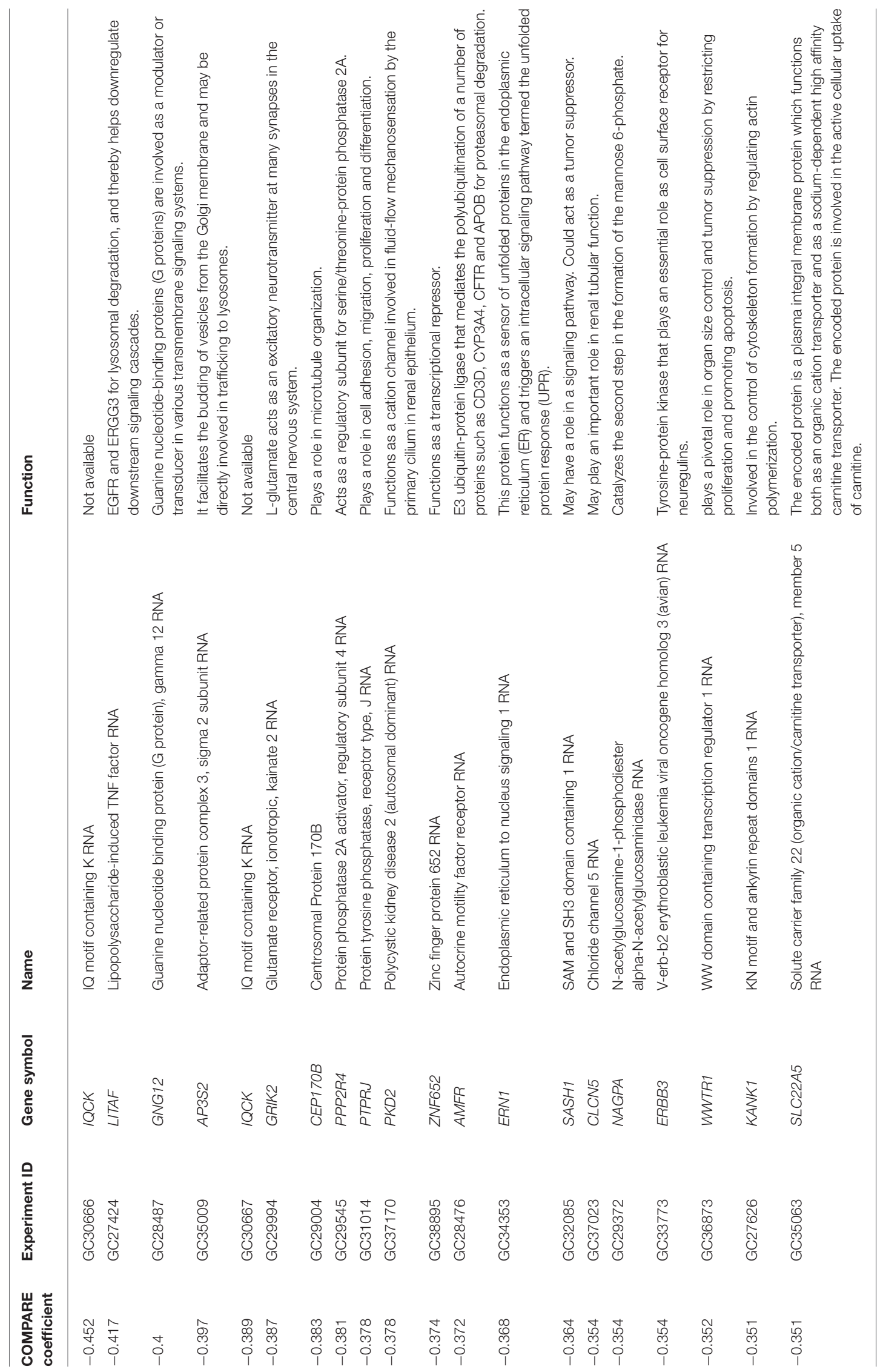




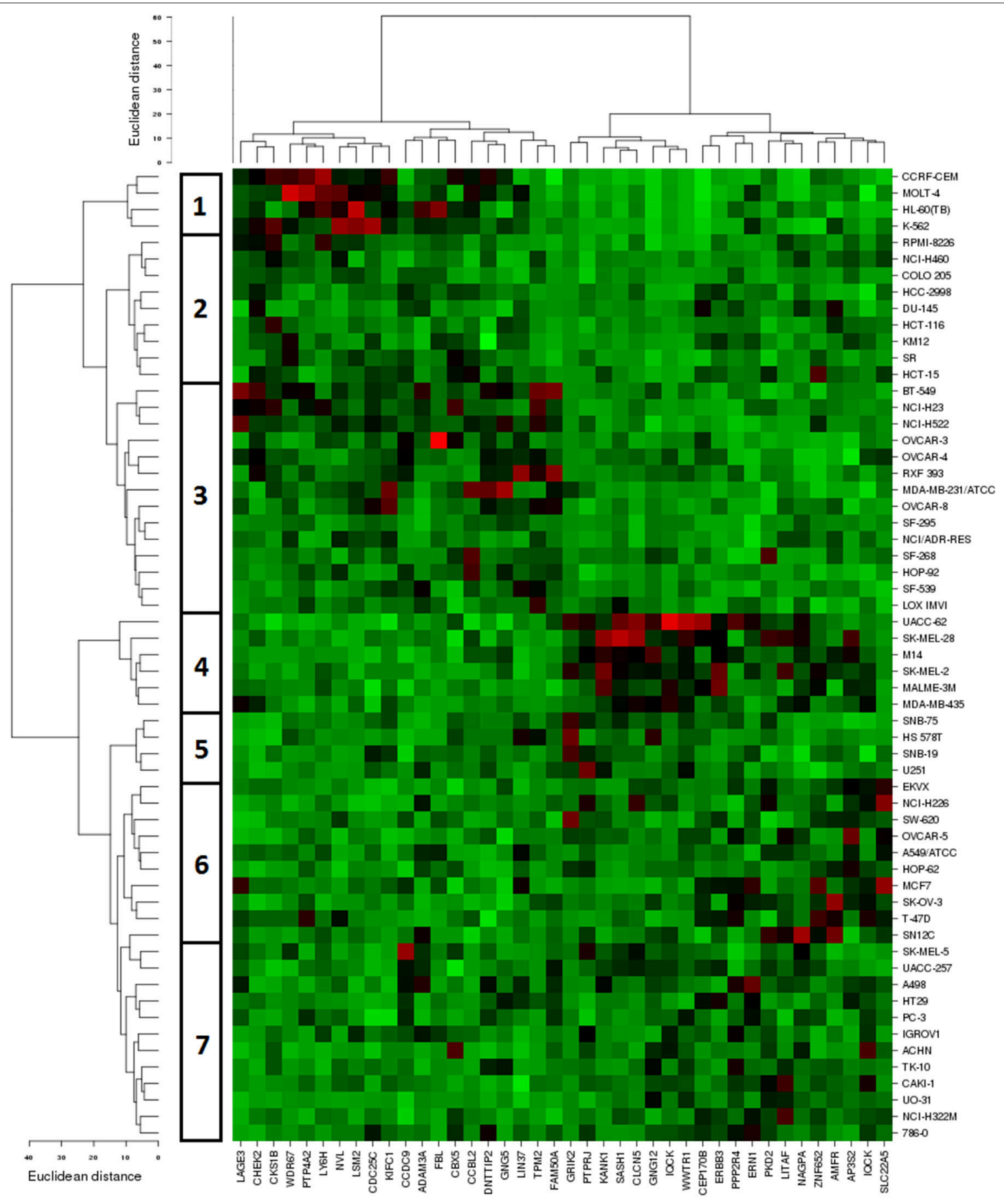

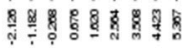

FIGURE 3 | Dendrograms and heatmap of BetA obtained by hierarchical cluster analyses of $\mathrm{NCl}$ cells line panel and genes whose mRNA expression directly or inversely correlated with the $\log _{10} I_{50}$ values for BetA. The dendrogram on the left shows the clustering of cell lines. 


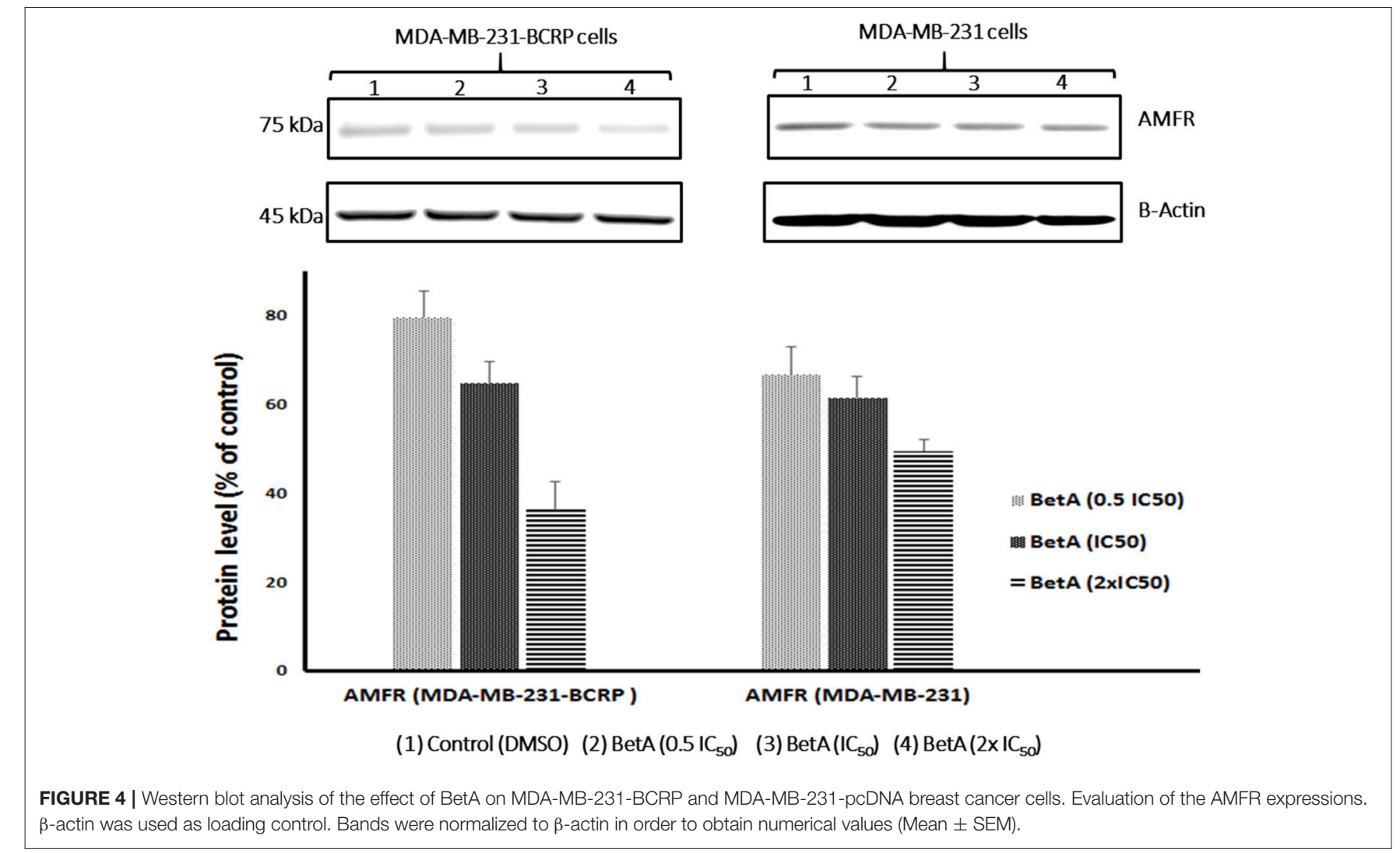

TABLE 3 | Molecular docking for BetA to different AMFR domains and its ligand AMF.

$\begin{array}{cccc}\text { Macromolecules PDB ID } & \begin{array}{c}\text { Lowest binding } \\ \text { energy } \\ \mathrm{kcal} / \mathrm{mol}\end{array} & \text { pKi }(\mu \mathrm{M}) & \begin{array}{c}\text { AA involved } \\ \text { in H-bonds }\end{array}\end{array}$

\begin{tabular}{|c|c|c|c|c|}
\hline \multicolumn{5}{|c|}{ The CYTOSOLIC C-TERMINAL TAIL OF AMFR INCLUDES } \\
\hline $\begin{array}{l}\text { Ubiquitin binding } \\
\text { CUE motif }\end{array}$ & $4 \mathrm{G} 30$ & $-6.69 \pm 0.07$ & $12.45 \pm 1.57$ & $\begin{array}{l}\text { Arg } 497 \\
\text { Gln478 }\end{array}$ \\
\hline $\begin{array}{l}\text { E2 binding } \\
\text { domain }\end{array}$ & $4 L A D$ & $-6.36 \pm 0.02$ & $21.26 \pm 0.36$ & $\begin{array}{l}\text { Lys } 595, \text { Gln } \\
591\end{array}$ \\
\hline $\begin{array}{l}\text { p97NCP } \\
\text { binding domain }\end{array}$ & 3TIW & $-6.73 \pm \leq 0.01$ & $11.66 \pm 0.05$ & Arg 636 \\
\hline
\end{tabular}

\section{LIGAND FOR AMFR}

AMF/PGI $\quad 1 \mathrm{NUH} \quad-7.22 \pm 0.06 \quad 5.14 \pm 0.57 \quad$ Thr 411

Shown are lowest binding energy, predicted inhibition constant (Pki), amino acids (AA) involved in hydrogen bonding. Each docking experiment has been repeated three times.

(AMFR, LITAF). All of these mechanisms foster tumor progression.

The expression of AMFR is reported to correlate with solid tumors staging and survival rates (Wang et al., 2010a). As an ubiquitin E3 ligase protein, AMFR targets various proteins for degradation whose expression have an impact in cancer progression. For instance, the downregulation of AMFR-mediated ubiquitination of heat-shock proteins (HSPs) suppresses the metastasis of breast cancer (Chang et al., 2016). Worth to mention, the activation of AMFR by AMF can stimulate a signaling cascade, dependent on protein kinase $\mathrm{C}$, and upregulates the Rho-like GTPase, RhoA and RhoC (Tsutsumi et al., 2002). Rho-associated, coiled-coil containing protein kinase 2 (ROCK2), a member of the RhoC family, functions as molecular determinants in several cellular functions, including proliferation, apoptosis and metastasis (Wang et al., 2010b). Apoptosis resistance is one of the prosurvival mechanisms for cancer cells and mediates the MDR to established chemotherapeutic agents. Moreover, it has been reported that autophagy promoted the development of paclitaxel and vinorelbine in breast cancer cells through inhibition of apoptosis (Sun et al., 2015). Wang et al. proved that overexpression of AMFR increased the levels of antiapoptotic protein, Bcl-2, whereas downregulation of AMFR led to a significant decrease in the expression of Bcl-2 and increased early apoptosis (Wang et al., 2015). Furthermore, it has been shown that the cytokine, AMF, induced Apaf-1 and caspase-9 downregulation, leading to the apoptotic resistant phenotype in malignant cells (Haga et al., 2003). Considering the before mentioned studies, AMFR could be an attractive target for refractory and metastatic cancers therapy. Halwani et al., have coupled paclitaxel with AMF to target AMFR, they demonstrated that AMF represents a useful delivery vehicle for paclitaxel to AMFR overexpressing cancer cells in vitro and in vivo. The AMF-paclitaxel conjugate inhibited colon and breast 


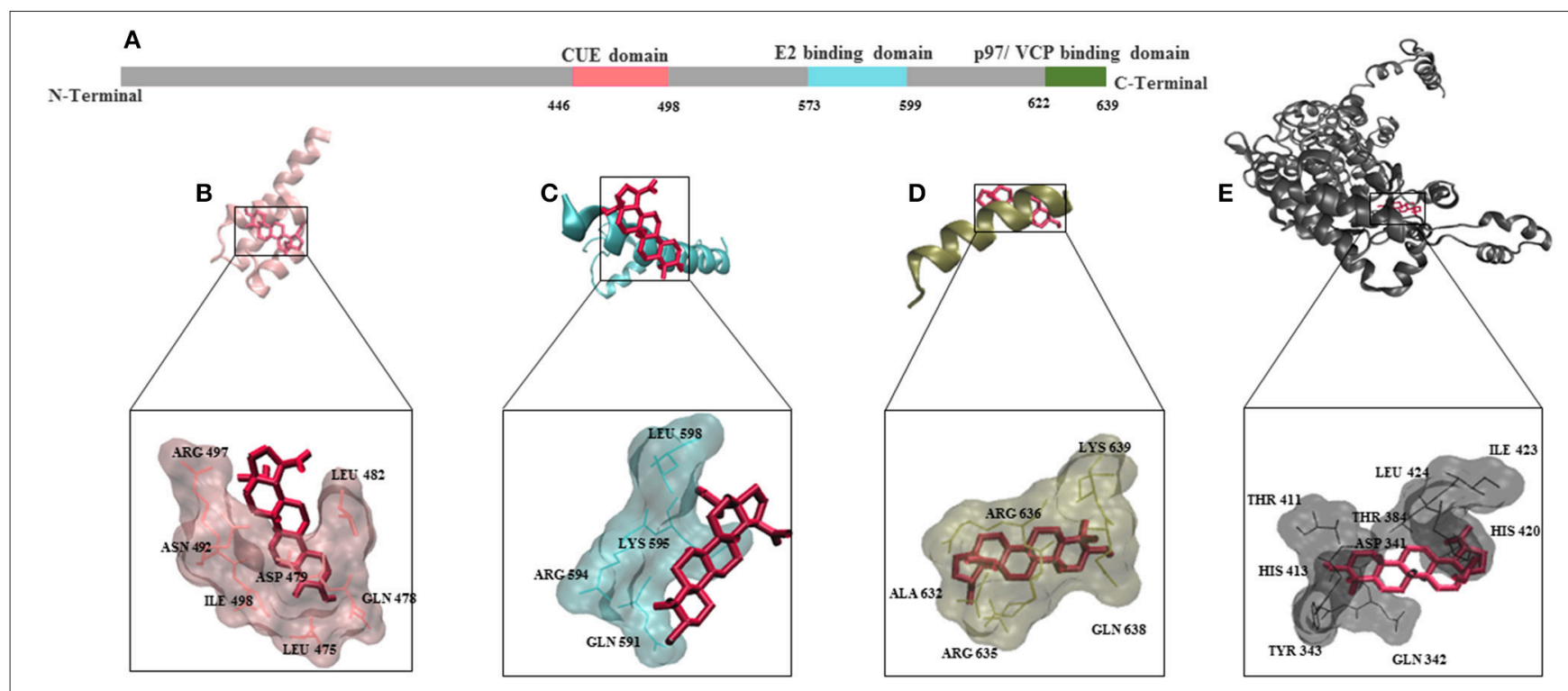

FIGURE 5 | Molecular docking for BetA to AMFR (Autocrine Motility Factor Receptor) and its ligand AMF. (A) Schematic aligning structure of AMFR transmembrane domains at the $\mathrm{N}$-terminal and cytosolic domains at C-terminal tail. (B) CUE domain functions to help substrate binding for ubiquitination. (C) E2 ubiquitin-conjugating enzyme binding domain. (D) p97NCP binding domain that participates in the final step of endoplasmic reticulum-associated degradation. (E) Autocrine Motility factor ligand. The proteins were depicted in a new carton format, whereas BetA was represented in dynamic bond format with red color.

cancer cells proliferation more effectively than free paclitaxel. Intra-tumoral injection of the AMF-paclitaxel conjugate also induced more effective tumor regression and increased survival in $\mathrm{K} 1735 \mathrm{M} 1$ and B16-F1/paclitaxel resistant mouse melanoma models (Halwani et al., 2015). Intriguingly, BetA was able to inhibit AMFR in a dose dependent manner. Additionally, our molecular docking analysis revealed that BetA has higher affinity to bind AMF, suggesting that the AMF coupling might be an attractive approach to potentiate BetA's activity in tumor cells.

The cell cycle is a highly controlled process that is regulated by the expression of cyclins, cyclin-dependent kinases (CDKs), inhibitors of CDKs and tumor suppressors (p53, Rb). Many tumor cells overexpress CDKs increasing their proliferative capacity. CDK-cyclin complexes tightly monitor the four sequential phases of cell cycle, namely G1, S, G2, and M phase, and dysregulation in any phase results in uncontrolled cell growth (Asghar et al., 2015). Overexpression of CDK4 found to be linked to the development of paclitaxel resistance in ovarian cancer cells. Recently, Gao et al. reported that inhibition of CDK4 by palbociclib resensitized both $\mathrm{Rb}$-positive and $\mathrm{Rb}$-negative MDR ovarian cancer cells with paclitaxel by increasing apoptosis (Gao et al., 2017). In this study, genes involved in cell cycle regulation appeared as a determinant of BetA's activity in the NCI cell lines. This coincides with previous studies showing that BetA arrested the cell cycle at the G1 phase, induced apoptosis through the mitochondrial pathway, and inhibited angiogenesis in breast cancer cells (Damle et al., 2013; Hsu et al., 2015). The mechanisms by which BetA induced cell cycle arrest included increased expression of p53 and p21 (Foo et al., 2015), mitochondrial perturbations (Fulda and Kroemer, 2009), and downregulation of anti-apoptotic Bcl-2 family proteins (Bcl-2, Bcl-XL) (Foo et al., 2015).

Signal transducers are frequently mutated in tumor cells, playing a significant role in tumorigenesis and drug resistance (Quintás-Cardama and Verstovsek, 2013). BetA downregulated the activation of STAT3 through the upregulation of $\mathrm{Src}$ homology 2 domain-containing phosphatase 1 (SHP-1), and affected the STAT3/HIF-1/VEGF signal pathway (Shin et al., 2011). Therefore, it is not surprising that the STAT3 upstream signal activator, $E R B B 3$, and protein phosphatase $2 \mathrm{~A}$ activator, $P P P 2 R 4$, appeared as molecular determinants for BetA's activity in our COMPARE analysis.

Modulation of chromatin is essential for cellular proliferation and deregulation in the degree of compaction of chromatin plays a pivotal role in the control of gene expression, replication, and repair and of chromosome segregation (Croce, 2008). The basic skeleton blocks of chromatin are nucleosomes that are composed of 146 base pairs of DNA wrapped around an octamer containing two each of four core DNA packaging proteins, i.e., the histones $\mathrm{H} 2 \mathrm{~A}, \mathrm{H} 2 \mathrm{~B}, \mathrm{H} 3$, and $\mathrm{H} 4$. The nucleosomes are further folded with the aid of linker histone $\mathrm{H} 1$ and non-histone proteins into an ordered, compact nucleoprotein complex (Thomas and Kornberg, 1975; Saha et al., 2006). Chromatin is a critical regulator of transcription and tumor suppressor genes. Therefore, deregulation of chromatin leads to genes activation and/or inappropriate genes silencing (Nair and Kumar, 2012). In our analysis, genes involved in chromatin remodeling and tumor suppression were identified as sensitivity determinants to BetA.

Furthermore, cell adhesion genes appeared as sensitivity determinants for BetA. Loss of cell-cell adhesive interaction 
represents an initiation step for invasion and metastasis of malignancies. It has been reported that BetA inhibits aminopeptidase $\mathrm{N}$, which is tightly associated with extracellular matrix components and involved in tumor cell invasion and metastatic activity during tumor development (Melzig and Bormann, 1998; Karna et al., 2010).

In conclusion, BetA exhibited remarkable cytotoxic activity against MDR cell lines. As shown in this study, the clinically established MDR conferring proteins (P-gp, BCRP, ABCB5 and $\triangle E G F R$ ) did not hamper BetA activity in tumor cells. Furthermore, microarray-based expression profiling of $60 \mathrm{NCI}$ cell lines revealed that BetA exerts cytotoxic activity toward cancer cells by multiple mechanisms rather than by a single one.

\section{REFERENCES}

Arteaga, C. L. (2002). Epidermal growth factor receptor dependence in human tumors: more than just expression? Oncologist 7(Suppl. 4), 31-39. doi: 10.1634/theoncologist.7-suppl_4-31

Asghar, U., Witkiewicz, A. K., Turner, N. C., and Knudsen, E. S. (2015). The history and future of targeting cyclin-dependent kinases in cancer therapy. Nat. Rev. Drug Discov. 14, 130-146. doi: 10.1038/nrd4504

Chandramu, C., Manohar, R. D., Krupadanam, D. G., and Dashavantha, R. V. (2003). Isolation, characterization and biological activity of betulinic acid and ursolic acid from Vitex negundo L. Phytother. Res. 17, 129-134. doi: $10.1002 /$ ptr. 1088

Chang, Y. W., Tseng, C. F., Wang, M. Y., Chang, W. C., Lee, C. C., Chen, L. T., et al. (2016). Deacetylation of HSPA5 by HDAC6 leads to GP78-mediated HSPA5 ubiquitination at K447 and suppresses metastasis of breast cancer. Oncogene 35, 1517-1528. doi: 10.1038/onc.2015.214

Chintharlapalli, S., Papineni, S., Ramaiah, S. K., and Safe, S. (2007). Betulinic acid inhibits prostate cancer growth through inhibition of specificity protein transcription factors. Cancer Res. 67, 2816-2823. doi: 10.1158/0008-5472.CAN-06-3735

Cichewicz, R. H., and Kouzi, S. A. (2004). Chemistry, biological activity, and chemotherapeutic potential of betulinic acid for the prevention and treatment of cancer and HIV infection. Med. Res. Rev. 24, 90-114. doi: 10.1002/med.10053

Croce, C. M. (2008). Oncogenes and cancer. N. Engl. J. Med. 358, 502-511. doi: 10.1056/NEJMra072367

Damle, A. A., Pawar, Y. P., and Narkar, A. A. (2013). Anticancer activity of betulinic acid on MCF-7 tumors in nude mice. Indian J. Exp. Biol. 51, 485-491.

Doyle, L. A., Yang, W., Abruzzo, L. V., Krogmann, T., Gao, Y., Rishi, A. K., et al. (1998). A multidrug resistance transporter from human MCF7 breast cancer cells. Proc. Natl. Acad. Sci. U.S.A. 95, 15665-15670. doi: $10.1073 /$ pnas.95.26.15665

Efferth, T., Sauerbrey, A., Olbrich, A., Gebhart, E., Rauch, P., Weber, H. O., et al. (2003). Molecular modes of action of artesunate in tumor cell lines. Mol. Pharmacol. 64, 382-394. doi: 10.1124/mol.64.2.382

Eiznhamer, D. A., and Xu, Z. Q. (2004). Betulinic acid: a promising anticancer candidate. IDrugs 7, 359-373.

Enwerem, N. M., Okogun, J. I., Wambebe, C. O., Okorie, D. A., and Akah, P. A. (2001). Anthelmintic activity of the stem bark extracts of Berlina grandiflora and one of its active principles, Betulinic acid. Phytomedicine 8, 112-114. doi: 10.1078/0944-7113-00023

Foo, J. B., Saiful Yazan, L., Tor, Y. S., Wibowo, A., Ismail, N., How, C. W., et al. (2015). Induction of cell cycle arrest and apoptosis by betulinic acidrich fraction from Dillenia suffruticosa root in MCF-7 cells involved p53/p21 and mitochondrial signalling pathway. J. Ethnopharmacol. 166, 270-278. doi: 10.1016/j.jep.2015.03.039

Fulda, S., Friesen, C., Los, M., Scaffidi, C., Mier, W., Benedict, M., et al. (1997). Betulinic acid triggers CD95 (APO-1/Fas)- and p53-independent apoptosis via activation of caspases in neuroectodermal tumors. Cancer Res. 57, 4956-4964.

Fulda, S., Jeremias, I., Steiner, H. H., Pietsch, T., and Debatin, K. M. (1999). Betulinic acid: a new cytotoxic agent against malignant brain-tumor cells. Int. J.
Summing up all findings in this study, we can postulate that BetA is a promising candidate with multiple modes of action to treat refractory tumors. Further investigations are needed to assure its efficacy and safety in vivo.

\section{AUTHOR CONTRIBUTIONS}

MS: carried out the in vitro experiments and wrote the manuscript; NM: performed COMPARE and cluster analysis; YS: provided ABCB5 transfected cell lines; HA-A: designed the bioassays and edited the manuscript; TE: supervised the work, provided the facilities for the study and edited the manuscript. All authors read the manuscript and approved the final version.

Cancer 82, 435-441. doi: 10.1002/(SICI)1097-0215(19990730)82:3<435::AIDIJC18>3.0.CO;2-1

Fulda, S., and Kroemer, G. (2009). Targeting mitochondrial apoptosis by betulinic acid in human cancers. Drug Discov. Today 14, 885-890. doi: 10.1016/j.drudis.2009.05.015

Fulda, S., Scaffidi, C., Susin, S. A., Krammer, P. H., Kroemer, G., Peter, M. E., et al. (1998). Activation of mitochondria and release of mitochondrial apoptogenic factors by betulinic acid. J. Biol. Chem. 273, 33942-33948. doi: $10.1074 /$ jbc. 273.51 .33942

Gao, Y., Shen, J., Choy, E., Mankin, H., Hornicek, F., and Duan, Z. (2017). Inhibition of CDK4 sensitizes multidrug resistant ovarian cancer cells to paclitaxel by increasing apoptosiss. Cell. Oncol. 40, 209-218. doi: 10.1007/s13402-017-0316-X

Genovese, I., Ilari, A., Assaraf, Y. G., Fazi, F., and Colotti, G. (2017). Not only Pglycoprotein: amplification of the $\mathrm{ABCB} 1$-containing chromosome region $7 \mathrm{q} 21$ confers multidrug resistance upon cancer cells by coordinated overexpression of an assortment of resistance-related proteins. Drug Resist. Updat. 32, 23-46. doi: 10.1016/j.drup.2017.10.003

Haga, A., Funasaka, T., Niinaka, Y., Raz, A., and Nagase, H. (2003). Autocrine motility factor signaling induces tumor apoptotic resistance by regulations Apaf-1 and Caspase-9 apoptosome expression. Int. J. Cancer 107, 707-714. doi: 10.1002/ijc.11449

Halwani, Y., Kojic, L. D., Chan, S. K., Phang, T. P., Masoudi, H., Jones, S. J., et al. (2015). Prognostic significance of autocrine motility factor receptor expression by colorectal cancer and lymph node metastases. Am. J. Surg. 209, 884-889. Discussion: 889. doi: 10.1016/j.amjsurg.2015.01.010

Hsu, R. J., Hsu, Y. C., Chen, S. P., Fu, C. L., Yu, J. C., Chang, F. W., et al. (2015). The triterpenoids of Hibiscus syriacus induce apoptosis and inhibit cell migration in breast cancer cells. BMC Complement. Altern. Med. 15:65. doi: 10.1186/s12906-015-0592-9

Huang, H. S., Nagane, M., Klingbeil, C. K., Lin, H., Nishikawa, R., Ji, X. D., et al. (1997). The enhanced tumorigenic activity of a mutant epidermal growth factor receptor common in human cancers is mediated by threshold levels of constitutive tyrosine phosphorylation and unattenuated signaling. J. Biol. Chem. 272, 2927-2935. doi: 10.1074/jbc.272.5.2927

Jung, G. R., Kim, K. J., Choi, C. H., Lee, T. B., Han, S. I., Han, H. K., et al. (2007) Effect of betulinic acid on anticancer drug-resistant colon cancer cells. Basic Clin. Pharmacol. Toxicol. 101, 277-285. doi: 10.1111/j.1742-7843.2007.00115.x

Karna, E., Szoka, L., and Palka, J. A. (2010). Betulinic acid inhibits the expression of hypoxia-inducible factor lalpha and vascular endothelial growth factor in human endometrial adenocarcinoma cells. Mol. Cell. Biochem. 340, 15-20. doi: 10.1007/s11010-010-0395-8

Kawanobe, T., Kogure, S., Nakamura, S., Sato, M., Katayama, K., Mitsuhashi, J., et al. (2012). Expression of human ABCB5 confers resistance to taxanes and anthracyclines. Biochem. Biophys. Res. Commun. 418, 736-741. doi: 10.1016/j.bbrc.2012.01.090

Kaynak, K., Kara, M., Oz, B., Akgoz, B., Sar, M., and Raz, A. (2005). Autocrine motility factor receptor expression implies an unfavourable prognosis in resected stage I pulmonary adenocarcinomas. Acta Chir. Belg. 105, 378-382. doi: 10.1080/00015458.2005.11679740 
Kho, D. H., Nangia-Makker, P., Balan, V., Hogan, V., Tait, L., Wang, Y., et al. (2013). Autocrine motility factor promotes HER2 cleavage and signaling in breast cancer cells. Cancer Res. 73, 1411-1419. doi: 10.1158/0008-5472.CAN-12-2149

Kimmig, A., Gekeler, V., Neumann, M., Frese, G., Handgretinger, R., Kardos, G., et al. (1990). Susceptibility of multidrug-resistant human leukemia cell lines to human interleukin 2-activated killer cells. Cancer Res. 50, 6793-6799.

Kojic, L. D., Joshi, B., Lajoie, P., Le, P. U., Cox, M. E., Turbin, D. A., et al. (2007). Raft-dependent endocytosis of autocrine motility factor is phosphatidylinositol 3-kinase-dependent in breast carcinoma cells. J. Biol. Chem. 282, 29305-29313. doi: 10.1074/jbc.M704069200

Kuan, C. T., Wikstrand, C. J., and Bigner, D. D. (2000). EGFRvIII as a promising target for antibody-based brain tumor therapy. Brain Tumor Pathol. 17, 71-78. doi: $10.1007 / \mathrm{BF} 02482738$

Kuete, V., and Efferth, T. (2013). Molecular determinants of cancer cell sensitivity and resistance towards the sesquiterpene farnesol. Pharmazie 68, 608-615. doi: $10.1691 /$ ph.2013.6503

Li, F., Goila-Gaur, R., Salzwedel, K., Kilgore, N. R., Reddick, M., Matallana, C., et al. (2003). PA-457: a potent HIV inhibitor that disrupts core condensation by targeting a late step in Gag processing. Proc. Natl. Acad. Sci. U.S.A. 100, 13555-13560. doi: 10.1073/pnas.2234683100

Mayaux, J. F., Bousseau, A., Pauwels, R., Huet, T., Henin, Y., Dereu, N., et al. (1994). Triterpene derivatives that block entry of human-immunodeficiencyvirus type-1 into cells. Proc. Natl. Acad. Sci. U.S.A. 91, 3564-3568. doi: 10.1073/pnas.91.9.3564

Melzig, M. F., and Bormann, H. (1998). Betulinic acid inhibits aminopeptidase N activity. Planta Med. 64, 655-657. doi: 10.1055/s-2006-957542

Monga, M., and Sausville, E. A. (2002). Developmental Therapeutics Program at the NCI: molecular target and drug discovery process. Leukemia 16, 520-526. doi: 10.1038/sj.leu.2402464

Nair, S. S., and Kumar, R. (2012). Chromatin remodeling in cancer: a gateway to regulate gene transcription. Mol. Oncol. 6, 611-619. doi: 10.1016/j.molonc.2012.09.005

Nishikawa, R., Ji, X. D., Harmon, R. C., Lazar, C. S., Gill, G. N., Cavenee, W. K., et al. (1994). A mutant epidermal growth factor receptor common in human glioma confers enhanced tumorigenicity. Proc. Natl. Acad. Sci. U.S.A. 91, 7727-7731. doi: 10.1073/pnas.91.16.7727

Onishi, Y., Tsukada, K., Yokota, J., and Raz, A. (2003). Overexpression of autocrine motility factor receptor (AMFR) in NIH3T3 fibroblasts induces cell transformation. Clin. Exp. Metastasis 20, 51-58. doi: 10.1023/A:1022594503657

Pengsuparp, T., Cai, L., Fong, H. H., Kinghorn, A. D., Pezzuto, J. M., Wani, M. C., et al. (1994). Pentacyclic triterpenes derived from Maprounea africana are potent inhibitors of HIV-1 reverse transcriptase. J. Nat. Prod. 57, 415-418. doi: $10.1021 / \mathrm{np} 50105 \mathrm{a} 017$

Quintás-Cardama, A., and Verstovsek, S. (2013). Molecular pathways: Jak/STAT pathway: mutations, inhibitors, and resistance. Clin. Cancer Res. 19, 1933-1940. doi: 10.1158/1078-0432.CCR-12-0284

Raghuvar Gopal, D. V., Narkar, A. A., Badrinath, Y., Mishra, K. P., and Joshi, D. S. (2005). Betulinic acid induces apoptosis in human chronic myelogenous leukemia (CML) cell line K-562 without altering the levels of Bcr-Abl. Toxicol. Lett. 155, 343-351. doi: 10.1016/j.toxlet.2004.06.015

Saeed, M. E., Mahmoud, N., Sugimoto, Y., Efferth, T., and Abdel-Aziz, H. (2018). Molecular determinants of sensitivity or resistance of cancer cells toward sanguinarine. Front. Pharmacol. 9:136. doi: 10.3389/fphar.2018.00136

Saha, A., Wittmeyer, J., and Cairns, B. R. (2006). Chromatin remodelling: the industrial revolution of DNA around histones. Nat. Rev. Mol. Cell Biol. 7, 437-447. doi: 10.1038/nrm 1945

Schühly, W., Heilmann, J., Calis, I., and Sticher, O. (1999). New triterpenoids with antibacterial activity from Zizyphus joazeiro. Planta Med. 65, 740-743. doi: 10.1055/s-1999-14054

Setzer, W. N., Setzer, M. C., Bates, R. B., and Jackes, B. R. (2000). Biologically active triterpenoids of Syncarpia glomulifera bark extract from Paluma, north Queensland, Australia. Planta Med.66, 176-177. doi: 10.1055/s-2000-11129

Shimizu, K., Tani, M., Watanabe, H., Nagamachi, Y., Niinaka, Y., Shiroishi, T., et al. (1999). The autocrine motility factor receptor gene encodes a novel type of seven transmembrane protein. FEBS Lett. 456, 295-300. doi: 10.1016/S0014-5793(99)00966-7

Shin, J., Lee, H. J., Jung, D. B., Jung, J. H., Lee, H. J., Lee, E. O., et al. (2011). Suppression of STAT3 and HIF-1 alpha mediates anti-angiogenic activity of betulinic acid in hypoxic PC-3 prostate cancer cells. PLOS ONE 6:e21492 doi: 10.1371/journal.pone.0021492

Shinojima, N., Tada, K., Shiraishi, S., Kamiryo, T., Kochi, M., Nakamura, H., et al. (2003). Prognostic value of epidermal growth factor receptor in patients with glioblastoma multiforme. Cancer Res. 63, 6962-6970.

Siddiqui, B. S., Sultana, I., and Begum, S. (2000). Triterpenoidal constituents from Eucalyptus camaldulensis var. obtusa leaves. Phytochemistry 54, 861-865. doi: 10.1016/S0031-9422(00)00058-3

Silletti, S., Watanabe, H., Hogan, V., Nabi, I. R., and Raz, A. (1991). Purification of B16-F1 melanoma autocrine motility factor and its receptor. Cancer Res. 51, 3507-3511.

Sun, W. L., Lan, D., Gan, T. Q., and Cai, Z. W. (2015). Autophagy facilitates multidrug resistance development through inhibition of apoptosis in breast cancer cells. Neoplasma 62, 199-208. doi: 10.4149/neo 2015_025

Tezuka, Y., Stampoulis, P., Banskota, A. H., Awale, S., Tran, K. Q., Saiki, I., et al. (2000). Constituents of the Vietnamese medicinal plant Orthosiphon stamineus. Chem. Pharm. Bull. 48, 1711-1719. doi: 10.1248/cpb.48.1711

Thomas, J. O., and Kornberg, R. D. (1975). An octamer of histones in chromatin and free in solution. Proc. Natl. Acad. Sci. U.S.A. 72, 2626-2630. doi: $10.1073 /$ pnas.72.7.2626

Tímár, J., Rásó, E., Döme, B., Ladányi, A., Bánfalvi, T., Gilde, K., et al. (2002). Expression and function of the AMF receptor by human melanoma in experimental and clinical systems. Clin. Exp. Metastasis 19, 225-232. doi: 10.1023/A:1015595708241

Tiwari, R., Puthli, A., Balakrishnan, S., Sapra, B. K., and Mishra, K. P. (2014). Betulinic acid-induced cytotoxicity in human breast tumor cell lines MCF7 and T47D and its modification by tocopherol. Cancer Invest. 32, 402-408. doi: 10.3109/07357907.2014.933234

Tsutsumi, S., Gupta, S. K., Hogan, V., Collard, J. G., and Raz, A. (2002). Activation of small GTPase Rho is required for autocrine motility factor signaling. Cancer Res. 62, 4484-4490.

Ueda, K., Cornwell, M. M., Gottesman, M. M., Pastan, I., Roninson, I. B., Ling, V., et al. (1986). The mdr1 gene, responsible for multidrug-resistance, codes for P-glycoprotein. Biochem. Biophys. Res. Commun. 141, 956-962. doi: 10.1016/S0006-291X(86)80136-X

Wang, L., Hou, G., Xue, L., Li, J., Wei, P., and Xu, P. (2010a). Autocrine motility factor receptor signaling pathway promotes cell invasion via activation of ROCK-2 in esophageal squamous cell cancer cells. Cancer Invest. 28, 993-1003. doi: 10.3109/07357907.2010.483503

Wang, L., Xue, L., Yan, H., Li, J., and Lu, Y. (2010b). Effects of ROCK inhibitor, Y-27632, on adhesion and mobility in esophageal squamous cell cancer cells. Mol. Biol. Rep. 37, 1971-1977. doi: 10.1007/s11033-0099645-9

Wang, Y., Ma, L., Wang, C., Sheng, G., Feng, L., and Yin, C. (2015). Autocrine motility factor receptor promotes the proliferation of human acute monocytic leukemia THP-1 cells. Int. J. Mol. Med. 36, 627-632. doi: 10.3892/ijmm.2015.2267

Woldemichael, G. M., Singh, M. P., Maiese, W. M., and Timmermann, B. N. (2003). Constituents of antibacterial extract of Caesalpinia paraguariensis Burk. Z. Naturforsch. C. 58, 70-75. doi: 10.1515/znc-2003-1-213

Yi, J. H., Zhang, G. L., Li, B. G., and Chen, Y. Z. (2000). Two glycosides from the stem bark of Tetracentron sinense. Phytochemistry 53, 1001-1003. doi: 10.1016/S0031-9422(99)00457-4

Conflict of Interest Statement: HA-A was employed by Steigerwald, Darmstadt, Germany.

The other authors declare that the research was conducted in the absence of any commercial or financial relationships that could be construed as a potential conflict of interest.

Copyright (c) 2018 Saeed, Mahmoud, Sugimoto, Efferth and Abdel-Aziz. This is an open-access article distributed under the terms of the Creative Commons Attribution License (CC BY). The use, distribution or reproduction in other forums is permitted, provided the original author(s) and the copyright owner are credited and that the original publication in this journal is cited, in accordance with accepted academic practice. No use, distribution or reproduction is permitted which does not comply with these terms. 